\title{
Test-system design for hydraulic solenoid valve of exhaust nozzle exit of
}

\section{a certain aeroengine}

\author{
Ren Zaiqing ${ }^{1, a}$, Zhu Dan ${ }^{2, b}$ \\ ${ }^{1,2}$ The First Aviation College of Air Force of PLADepartment of Aviation Mechanical Engineering, \\ Xin Yang, Henan, China \\ a,bhkniu@sohu.com
}

Key Words:aero-engine;solenoid valve; test-system

Abstract:Based on the test requirement of hydraulic solenoid valve of exhaust nozzle exit of a certain aero-engine, the test-system ofthe hydraulic solenoid valveis designed. The test-systemconsists of a pneumatic unit,a control measure unit and a software unit. It can be used to perform the performance parameter test of thehydraulic solenoid valve. Thetest-system is fulfilled the needs of fighter repair factories and worked in good condition.

\section{Introduction}

An aero-engine nozzle solenoid valve is used to control the oil circuit of actuator for receive and put nozzle, manipulation of the nozzle actuator work to change the diameter of the nozzle. If the nozzle solenoid valve breaks down because of state transition or internal leakage, nozzle adjustment can't work normally, which will affects the normal work of the engine, even cause air parking, lead to accident. At present, the performance of the nozzle solenoid valve test adopt points module mode, which including many test links and many parameters has low test efficiency. The design of aero-engine nozzle solenoid valve testing system is according to the features of nozzle solenoid valve, based on "Appendix Operating Manual" and "Engine Accessories and Maintenance Standards". The system is integrated test equipment which Adopted many new technology such as computer control, state monitoring, parameter collection and processing. This system can also be extended to performance test for other different type nozzle hydraulic solenoid valve.

\section{Working principle and testing content of the nozzle solenoid valve}

\section{Working principle}

This is the nozzle solenoid valve's structure, as shown in figure 1. 


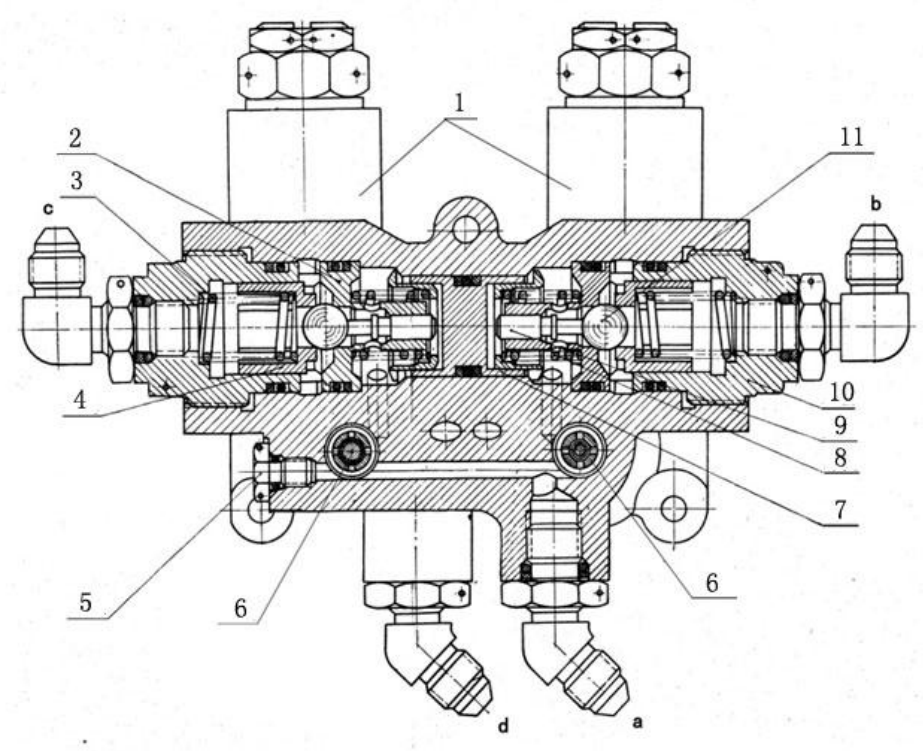

Fig.1 Configuration of the YDF-16
1. Electronic coil
2. valve seat 3 . spring
4. guide sleeve
5. blocking
6. valve
7.plunger
8. spring 9. mandril 10. swivel nut 11. steel ball-type valve

The valve is mainly composed of shell, solenoid valve, double hydraulic lock, expansion valve, etc. There are four ports on the shell: Port a pick up oil pump, Port d pick up fuel tank, Port b pick up close chamber of nozzle actuator cylinder, Port c picks up release chamber of nozzle actuator cylinder. When both the solenoid valve power outages, the valve plugs to oil under the action of spring force. Two valves of double hydraulic lock automatically shut down, the actuating cylinder enclosed two working chambers, the piston rod can't move, nozzle diameter is constant. When the close solenoid valve electricity, solenoid valve moves left, connected to oil, plug up outlet oil line, open to the right oil valve of hydraulic lock. The actuator cylinder takes back because of oil into the close chamber, the nozzle diameter smaller. The release solenoid valve electricity, work with similar, only parts movement in the opposite direction, enlarge the nozzle diameter.

\section{Testing content}

According to the aircraft nozzle solenoid valve working principle and the use of technical standards, the main test content including:

(1) Leakage test

When the electromagnet power outages, hydraulic pressure of $315 \mathrm{~kg} / \mathrm{cm} 2$ was applied to port $\mathrm{b}$ and port c. After six minutes, external examination should be sealed, port c should be sealed. When port $\mathrm{b}$ and port $\mathrm{c}$ were blocked over, and the port $\mathrm{d}$ was connected to the outlet oil line, hydraulic pressure of $315 \mathrm{~kg} / \mathrm{cm} 2$ was applied to port a, two electromagnets were electricity, keep 6 minutes, each junction should be sealed.

(2) The expansion valve adjustment test

Pressure was applied to port c, adjust the expansion valve opening pressure to $260 \pm 20 \mathrm{~kg} / \mathrm{cm} 2$. When the expansion valve was opened, oil should be dropped from port d. Repeat test $3 \sim 5$ times, Open pressure of the expansion valve was allowed lower than the original setting, but not more than 5 $\mathrm{kg} / \mathrm{cm} 2$, and keep in the range of $260 \pm 20 \mathrm{~kg} / \mathrm{cm} 2$. Check the close pressure of the expansion valve should not be less than $220 \mathrm{~kg} / \mathrm{cm} 2$. 


\section{(3) Performance test}

When working temperature is $20 \pm 10^{\circ} \mathrm{C}$, port b and port c connected to the actuator cylinder, port $\mathrm{d}$ connected to outlet oil line, hydraulic pressure of $60 \mathrm{~kg} / \mathrm{cm} 2$ was applied to port a. Electromagnet "put down" to electricity, the piston rod of actuator cylinder should be stretched out. When the electromagnet was power down, the piston rod should stop. Electromagnet "up" to electricity, the piston rod of actuator cylinder should be received. When the electromagnet was power down, the piston rod should stop. Respectively on and off these electromagnets $3 \sim 5$ times, the work should be accurate.

Port $\mathrm{b}$ and port $\mathrm{c}$ connected to the actuator cylinder, port $\mathrm{d}$ connected to outlet oil line, hydraulic pressure of $60 \mathrm{~kg} / \mathrm{cm} 2$ was applied to port a. and the return pressure was regulated to $20 \pm 3 \mathrm{~kg} / \mathrm{cm} 2$, Respectively on and off these electromagnets $3 \sim 5$ times, the work should be accurate without block phenomenon.

Port c connected to a sealed container, port b connected to hand pump, hydraulic pressure of $210 \mathrm{~kg} / \mathrm{cm} 2$ was applied to port a. and the pressure of sealed container was $210 \mathrm{~kg} / \mathrm{cm} 2$, when the electromagnet was power down, pressure of sealed container should not lower than $190 \mathrm{~kg} / \mathrm{cm} 2$. At the same time, oil leakage volume of port $\mathrm{d}$ should not exceed $10 \mathrm{~cm} 2$ within three minutes. According to the above operation method, monitor the performance of the port b should comply with the requirements.

\section{Test system component}

The test system to simulate the real working environment of accessory be measured, so that the performance parameters of the preparation of measurement, design of test system is mainly composed of hydraulic system, the computer control system, the measurement and control software.

\subsection{Hydraulic system principle}

Hydraulic system composed of two parts, as shown in figure 2, figure 3, respectively. Figure 2 is mainly used for sealing test, including fuel tank, hydraulic pump, oil filter, accumulator, pressure regulating valve, switch, etc. Figure 3 is mainly used for adjustment test and performance test for expansion valve, including fuel tank, hydraulic pump, hand pump, oil filter, accumulator, overflow valve, switch, pressure gauge, measured parts, cylinder, etc. Two parts of the hydraulic system established separately in different test bed body, the function is for the establishment of the system test condition and transformation. And control the oil flow of four ports in the process of test. At the same time using the D/I, D/O board to collect oil filter working status (alarm), temperature sensor (over temperature) data working status, and control in a timely manner. Measured the nozzle solenoid valve required for pressure, flow rate by the hydraulic system of the overflow valve, and pressure, flow rate sensor by industrial D/O, D/A and A/D board set, adjusting and measuring records. 


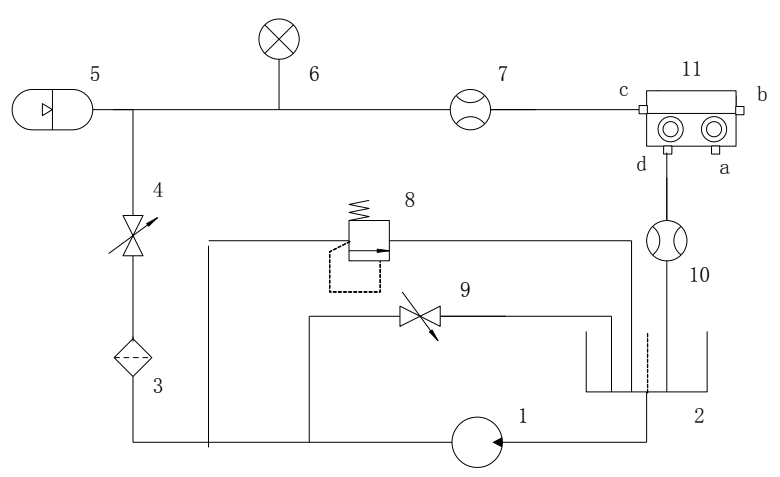

Fig.2 Thetheory ofhydraulic pressure system

1. Hydraulic pump 2. The fuel tank 3.The oil filter 4.9.switch 5.accumulator 6.Pressure gauge and sensor 7.10.Flow sensor 8 . The overflow valve 11. measured piece

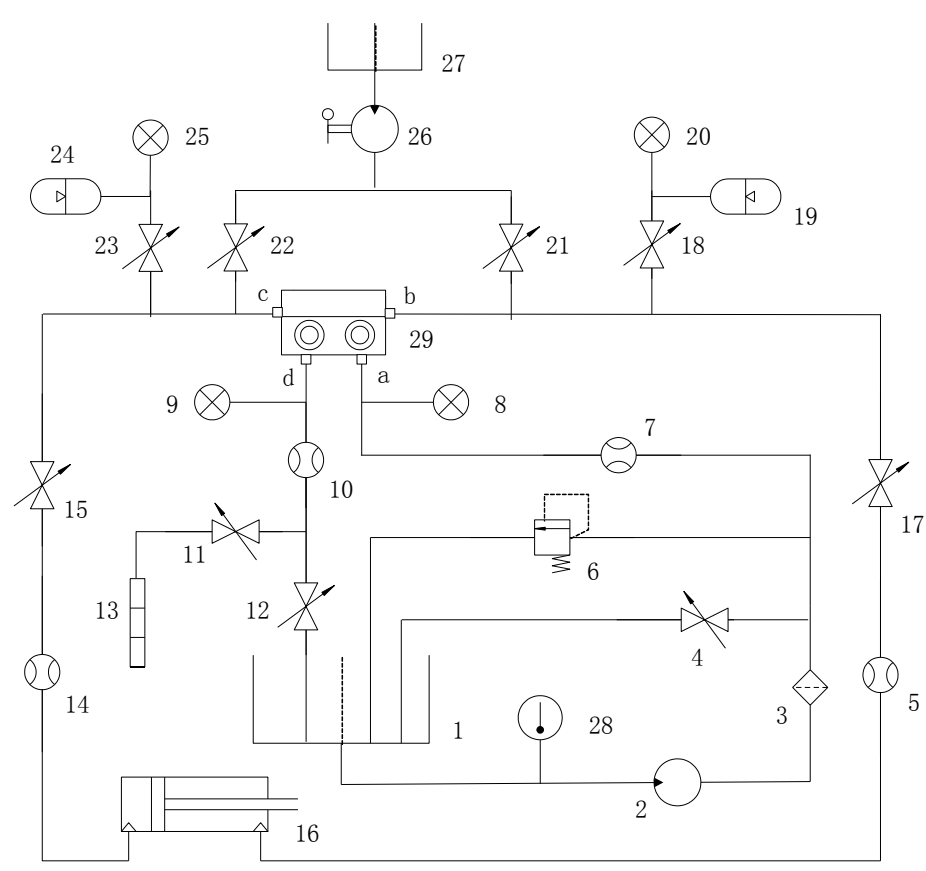

Fig.3 The theory ofhydraulic pressure system

1.27.The fuel tank 2.Hydraulic pump 3.The oil filter 4.11.12.15.17.switch 5.7.10.14. The flow sensor 6.The overflow valve 8.9.20.25.Pressure gauge and sensor 13.Measuring cylinder 19.24.Actuating cylinder 19.24.accumulator 18.21.22.23. The electric switch 26.Hand pump

\section{Computer control principle}

Computer control system is mainly composed of data collection and input part, Industrial computer, data conversion output part, power equipment, etc. Data collection and input part is mainly composed of pressure sensor, flow sensor, temperature sensor, analog signal conversion board, switch signal conversion board, timer/counter, and the corresponding connection test circuit, etc. Data conversion output part is composed of multiplex DIDO plate and D/A conversion board, terminal board and all kinds of electromagnetic valve, the oil pump motor, oil temperature control electromagnetic part of attachment, and the composition of connected conversion circuit. Industrial computer connected with the keyboard, mouse, printing equipment, internal furnish measurement and control software, can stimulate the analog-to-digital conversion board. Measurement and control software according to the pre-determined plan to change the state of nozzle solenoid valves. Implement solenoid valve data collection, conversion, and output. Test data can be timely response 
on display devices of the test board, can print and analysis when necessary.

\section{Measure and control software}

Measurement and control software is running under the Windows 7 system, using Visual Studio 2013 software development. Software interface is simple and easy to manipulate. Nozzle solenoid valves of various state transformation through menu and form, with the mouse click to complete the switch. And various state test results form through the form at the other side of the interface, a print button to print the test results, making it easy for users to analyze.

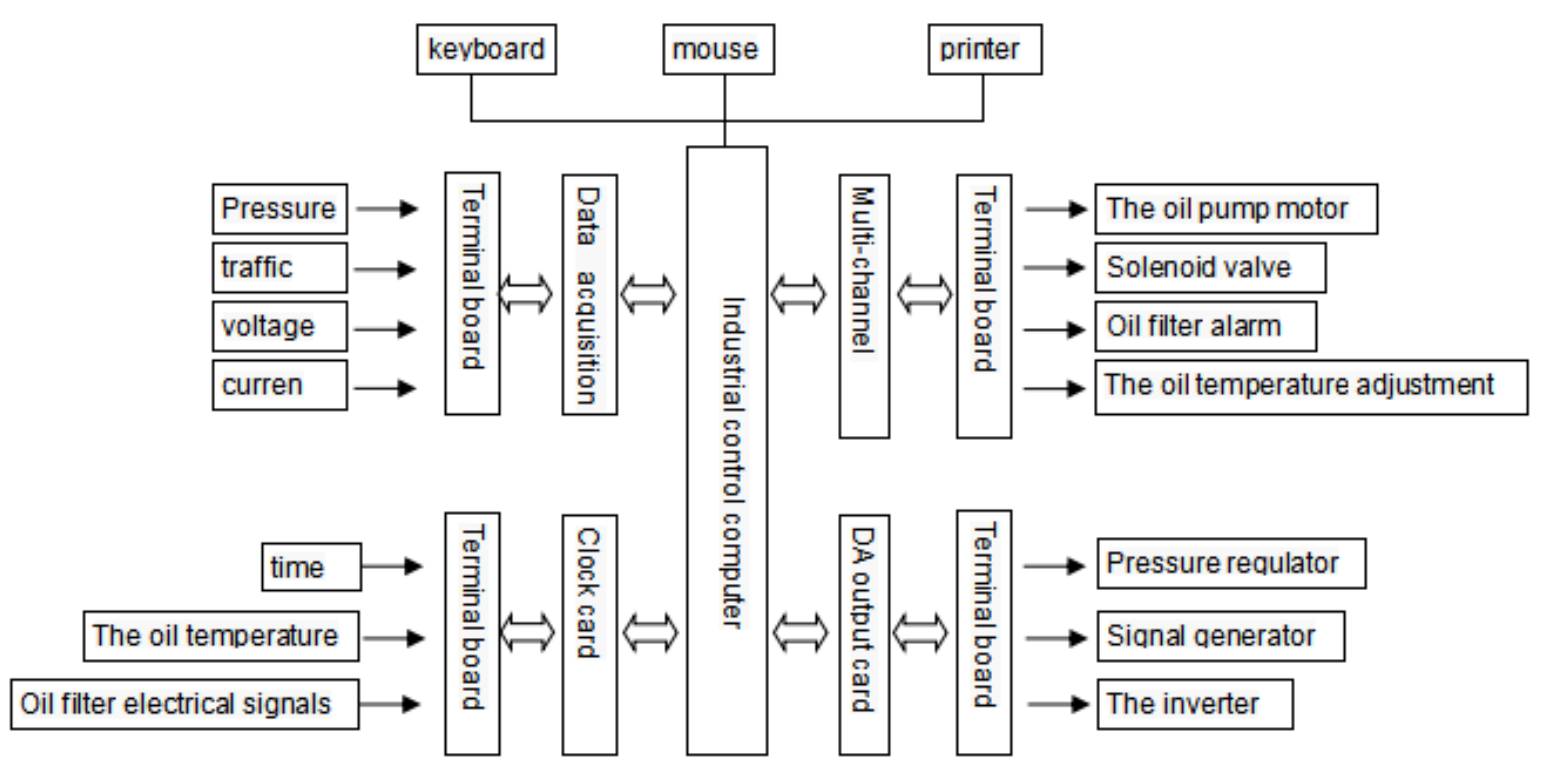

Fig. 4The theory of computer control system

\section{The main technology}

\section{Pressure and flow control solutions}

According to military aircraft of various kinds of electromagnetic valve "instruction manual" and "standard of accessories repair" and related testing requirements: under the condition of specific pressure, flow rate, the parameters such as nozzle solenoid valve sealing performance and working performance test. Through the industrial computer as the controller, using the measurement and control software according to the scheduled change rule, control the pressure sensor and pressure regulating valve work, realize nozzle solenoid valve pressure parameters of the PID control; Control flow sensor and the overflow valve, electromagnetic valve nozzle flow parameters of the PID control.

\section{Adopts hydraulic integration technology}

According to the characteristics of high test frequency for nozzle solenoid valve, require nozzle solenoid valve test device is easy to move, easy to maintenance. This test system by integrating the hydraulic circuit blocks will hydraulic components installed in each oil blocks on the hydraulic components can use plate installation, cartridge, such as return oil filter, check valve, choke, pressure regulator of oil hydraulic manifold blocks. By this way, the test device meet the requirements of the portable and good maintainability. 


\section{Conclusions}

This paper designed the test system of airborne electromagnetic valve of a certain aircraft, using industrial computer, D/I, D/O plate, various sensors, pressure regulating valve and so on with work, measured the actual working environment, simulation and real time measured job status, pressure and temperature data, and control, timely detection of solenoid valve working performance. Test system has good control is simple, interactive, accurate, safe and reliable test results, etc. The test system since delivery of the aircraft repair shop in 2011, has been fixed 10 batches of more than 50 pieces (sets), has solved the factory existing test device test efficiency is low, easy to pollution and damage to the thing being measured.

\section{Reference documents :}

[1] 99-J7B-FF, Nozzle Solenoid Valve Technology Conditions [s]

[2] RuShaoming. Aircraft Structure of Fighter and Attacker [M]. Blue Sky Press, 2001

[3] LiZhuangyun. Hydraulic Components and Systems [M]. Beijing: China Machine Press, 2011

[4] ShuaiChanghong. Hydraulic Equipment Design, Production, Technical Transformation Monitoring and Fault Diagnosis [M]. Beijing: The Northern Industrial Press, 2006

[5] Editorial Board for Mechanical Design Manual. Mechanical Design Manual: Hydraulic Transmission and Control [M]. Beijing: China Machine Press, 2007.

[6] FengXiaodi, ZhengBenfang. The Development of the Hydraulic Support with Valve Test Bench [J]. Chinese Hydraulics and Pneumatics, 2011

[7] WenBangchun. Mechanical Design Manual [M]. Beijing: China Machine Press, 2010

[8] WangKun. Course Exercise in Mechanical Design [M]. Beijing: Higher Education Press, 2007

[9] Huang Jianlong. Hydraulic Integrated Test Bench and Its Control System Research [J]. Chinese Hydraulics and Pneumatics, 2007

[10] ChengDaxian. Mechanical Design Manual: Hydraulic Transmission [M]. Beijing: Chemical Industry Press, 2004

[11] Li Ruping. Development of the Hydraulic Servo Valve Static Characteristic Test Bed [J]. Chinese Hydraulics and Pneumatics, 2008

[12] Hu Kongfa. Principle and Application of the Database [M]. Beijing: China Machine Press, 2008

[13] Liu Guochang. Research and Implementation of Hydraulic CAT Technology [J]. Colliery Mechanical \& Electrical Technology, 2006 